\title{
LOS PREJUICIOS \\ DEL INTERNACIONALISMO: ESPACIO, MODERNIDAD \\ Y AMBIVALENCIA ${ }^{1}$
}

Juan García García

Universidad Complutense

Uno de los problemas más difíciles de abordar en el estudio psicosocial del "prejuicio» durante el presente siglo ha sido, sin duda, el de explicar los repentinos cambios que el sujeto moderno ha experimentado en el proceso de «internacionalización» de sus coordenadas espaciales. Tratando esta cuestión, el ejemplo de la Alemania de entreguerras brota inmediatamente en la imaginación del investigador. Pero el problema no debiera ser acotado por sus casos más dramáticos, sino más bien por la generalidad y frecuencia de su aparición en la era de la Modernidad. Pudiera no ser casual que uno de los rasgos caracterizadores de la "época del nacionalismo» (Kohn, 1949) haya sido la tendencia periódica a anunciar su final, como diversos autores han señalado recientemente.

En este ensayo quisiera repensar las discutibles premisas que el estudio del nacionalismo ha asumido tradicionalmente para abordar esta cuestión. Frente

1 Tanto éste como un trabajo anterior — publicado igualmente por la REIS - forman parte de una trayectoria departamental en el estudio de las identidades nacionales que precede en el tiempo mi propia implicación en la materia. Debo, por tanto, agradecer al Departamento de Psicología Social de la Universidad Complutense de Madrid, y muy especialmente al profesor José Ramón Torregrosa, el contexto académico adecuado para su realización. Tanto el profesor Torregrosa como el profesor Eduardo Crespo me facilitaron - con sus observaciones- la versión definitiva que aquí se publica bajo mi única responsabilidad.

También me gustaría mencionar la inestimable ayuda que encontré en los comentarios del profesor E. Lamo de Espinosa. 
a una concepción restringida de nacionalismo como fenómeno «individual», "premoderno" y "dotado de coherencia cognitiva», sólo recientemente las Ciencias Sociales empiezan a considerar el nacionalismo bajo el prisma - ampliado - de las «identidades de grupo", asumiendo al mismo tiempo que la nación es asunto que concierne a la propia Modernidad.

Mi hipótesis fundamental será que, aceptadas mayoritariamente estas dos premisas, conscientes hoy de la dificultad de entender el nacionalismo desgajado del proceso de la inter(-)nacionalización de los espacios comunicativos de la Modernidad o, dicho de otra forma, concebida la Modernidad como el marco contradictorio donde - por antonomasia-coexisten el internacionalismo y el nacionalismo, será ya más fácil desembarazarse de la premisa anterior sobre la "coherencia espacial» del ciudadano moderno (sea o no sea etiquetado como "nacionalista»). Unicamente la ambivalencia de un sujeto fronterizo (o su dialogismo espacial) permiten a éste una permanente adecuación cognitiva en tan contradictorio entorno.

Es por eso que sólo la "radical disonancia» de la actitud moderna hacia «lo extranjero» o la intrínseca constitución de toda «identidad nacional» como experiencia fronteriza nos posibilita la comprensión de aquellos repentinos cambios en la vivencia moderna del espacio. En último término sugeriré que tal «ambivalencia espacial» no debiera ser asumida a regañadientes por el investigador: más que suponer periódicas dislocaciones en la constitución de una determinada «identidad nacional», la cadencia espacial de la Modernidad («internacionalismo-endogrupalidad») conforma la imprescindible gramática, la materia prima constitutiva de toda «identidad nacional».

\section{«PREJUICIO»: EL SENTIDO CAMBIANTE DEL TERMINO}

Voltaire ejemplificaba a menudo con España el mundo de religión establecida que, para él, como para la generación de los enciclopedistas (philosophes) congregados en los salones del XVIII, habría de desaparecer en la nueva era de la razón ilustrada. Sin duda, en el contexto sociopolítico de prolongada decadencia del absolutismo francés, los reunidos habitualmente en la casa del barón D'Holbach o en la de Helvétius repetían incesantemente sus críticas contra los prejuicios interesados y conscientes de clérigos y aristócratas. En la época de la publicación de la Enciclopedia se desarrolla la intención moral de los filósofos hasta hacerse, al menos indirectamente, política (Habermas, 1981).

Hubo que esperar a este siglo ilustrado para encontrar la palabra "prejuicio" entendida como "oposición a la racionalidad». Es entonces cuando algunas de sus acepciones adquieren las connotaciones negativas que hoy inevitablemente arrastra el término. Gadamer (1979) afirma que tales transformaciones semánticas estaban relacionadas con la tendencia de los ilustrados a no aceptar ninguna «autoridad» (y decidir todo ante el tribunal de la razón).

De este modo, el cambio semántico tenía también que ver con una deman- 
da de mayor libertad social y política. La voz «prejuicios» había sido escrita para la Encyclopedie (1765) por el Chevalier de Jaucourt, no tratándose sino de un comentario de la teoría de los «idola» de Bacon. Ahora bien, como nos recuerdan Lamo de Espinosa et al. (1994), mientras que en Bacon era el sujeto pensador el que «inconscientemente» se dejaba arrastrar por falsas nociones, representaciones ilusorias o apariencias que le alejaban de la certeza científica prometida, de este lado del Canal, y en un contexto de decadencia política, el error psicológico baconiano mutaba en error consciente, error que proviene de fuera, del engaño de los demás. Era el interés del poderoso, de las altas jerarquías eclesiásticas y de la aristocracia, el que de manera intencionada enmascaraba la verdad hasta engañar a las masas ignorantes que, finalmente, terminaban por autoengañarse.

Sin pretender en ningún modo agotar el campo semántico del término, es preciso atender a su complejidad y a las diferencias valorativas que al mismo se adherían. Los philosophes, según Billig (1991), lo emplean en determinados contextos sin el significado negativo que zahería a sacerdotes y aristócratas. Así, por ejemplo, en el ámbito de la educación, Voltaire señalaba la existencia de prejuicios justificables, tal como los que podrían disponer positivamente a un niño hacia su preceptor.

Billig nos habla de otro uso del término prejuicio que, por la connotación positiva que contiene, ha de producir inevitablemente cierta perplejidad al científico social contemporáneo. Me refiero a la acepción de prejuicio como "prejuicio nacional», entendido como virtud. Billig cita algún ejemplo: «El Registro Anual de 1787 incluía un breve ensayo titulado "Sobre el Prejuicio", reimpreso del tercer volumen de El Observador. El ensayo era claro en la condena de los prejuicios religiosos, al mismo tiempo que los distinguía de otros prejuicios. Así, por ejemplo, el autor afirmaba que (...) el "prejuicio nacional" debería ser visto como una "virtud" (trad. mía).

Por supuesto que desde los arrabales del pensamiento ilustrado era más fácil articular el citado uso de "prejuicio». Así, para J. G. Herder: «El prejuicio es bueno, en su tiempo, pues nos hace felices. Devuelve a los pueblos a su centro, los vincula sólidamente a su origen, los hace más florecientes de acuerdo con su carácter propio, más ardientes y, por tanto, también más felices en sus inclinaciones y objetivos» (citado en Pinillos, 1989).

Para el psicólogo social contemporáneo, no dejaría de ser contradictoria la defensa de un sentimiento nacional con la expresión «prejuicio nacional». Y es que en el siglo XX el sentido peyorativo de "prejuicio" no está capitalizado por «el engaño (consciente e interesado) de la clase sacerdotal», según la concibieron los enciclopedistas, sino por una nueva acepción de contenido en este caso peyorativo: la de "opiniones nacionalistas o racistas», como se deduce del repaso de la bibliografía psicosocial.

Ya durante la primera mitad de este siglo, el término "prejuicio» había ido adquiriendo mayor presencia institucional a partir de la problematización del «prejuicio racial» y el «prejuicio nacional». Con objeto de redactar una serie de 
principios generales sobre el funcionamiento psicológico del prejuicio, G. Allport (1958) dejó el término "prejuicio» sin calificativos en un trabajo —ya clásico- sobre la cuestión. No obstante, Allport pone el énfasis en los prejuicios racistas, nacionalistas y antisemitas, de modo que la ejemplificación daba contenido sustantivo a los principios generales.

Poco después, Rokeach (1963) afirmará: «(...) El análisis descubre que conceptos tales como intolerancia, discriminación, fanatismo, distancia social, prejuicio, actitudes racistas y etnocentrismo se definen todas operativamente de un modo parecido, determinando cómo los sujetos actúan o sienten respecto a los negros, judíos, extranjeros y similares.»

La asociación "prejuicio» y «nacionalismo» (o racismo) estaba contenida igualmente en la similitud semántica de "prejuicio» e "intolerancia», dando cuenta, además, de las connotaciones negativas que el término indefectiblemente tiene hoy en el entorno académico. Como nos recuerdan Wetherell y Potter (1992), «el prejuicio pasó a estar fuertemente asociado con el problema de la irracionalidad que todo ciudadano (postilustrado) decente desearía evitar. Por lo tanto, la oposición establecida entre prejuicio y racionalidad se especificó más estrechamente a lo largo del siglo XX, mostrándose como un contraste entre prejuicio y tolerancia» (trad. mía). Atiéndase también al cambio producido en el significado del término "tolerancia»: en su Tratado sobre la tolerancia, el empeño de Voltaire había sido el de pronunciar un severo juicio contra el clericalismo («nombre dado a la influencia del clero en los asuntos políticos»).

Para buena parte de la literatura psicosocial es irrelevante la hipotética fuerza centrípeta que Herder suponía al prejuicio («el prejuicio devuelve a los pueblos hacia su centro»). La definición de "prejuicio» se articula como problematización —en términos psicológicos - de las relaciones intergrupales: el prejuicio impide la apertura hacia el extranjero. Por eso, como nos recuerda Billig (1991), el uso de "prejuicio» va a menudo de la mano de la investigación psicosocial de imágenes y estereotipos exogrupales.

En cualquier caso, conviene llamar la atención sobre la importancia que ya de por sí podría tener el hecho de que la noción de prejuicio se haya articulado a lo largo del siglo XX en el campo de la nación (y de la raza), concretándose como problema en el ámbito de las relaciones intergrupales (relaciones internacionales o inter-raciales). Curioso resultado - a poco que se piense- el de comprobar que los guías ilustrados de una nueva sociedad vislumbraron — primero- la nueva era de la razón en oposición a la jerarquía religiosa, para terminar - al cabo de unas generaciones - personificando la idea de la antirrazón en el nacionalista. Curioso - como digo- porque si la concepción volteriana de "prejuicio" se anclaba en una de las relaciones sociales más característicamente premodernas (la que constituía la clase sacerdotal con el pueblo llano), la manejada por la Psicología Social lo está en la ejemplificada comúnmente por Voltaire (España como estereotipo de la premodernidad), que apunta a la creciente notoriedad de nuevos espacios comunitarios imaginados, como los del Estado moderno. 
No obstante, los psicólogos sociales — como los sociólogos- nunca consideraron al nacionalista un personaje plenamente inmerso en los procesos cotidianos de la Modernidad.

\section{LA SOCIOLOGIA Y LA PERDIDA DE LAS COORDENADAS ESPACIALES}

La prueba más contundente de que la Sociología ha concebido tradicionalmente el nacionalismo como un fenómeno fundamentalmente premoderno quizá sea la escasa atención que ha dispensado a su estudio. Si la investigación sobre el nacionalismo adquirió, al menos desde principios de siglo, un lugar en la Psicología Social (bajo el capítulo de los estudios sobre "prejuicio»), la Sociología ha desatendido, hasta hace pocas décadas, los procesos sociales que intervienen en la formación y evolución de naciones y nacionalismos, el estudio de las identidades nacionales y su interrelación con los procesos de la Modernidad.

¿Cómo podrían la lealtad étnica o regional, exclusivista y ensimismada, sobrevivir a la expansión de la razón ilustrada? ¿Cómo podrían aguantar el embate de la expansión del comercio y de la técnica? ¿Cómo sobrevivirían a la división internacional del trabajo? Para Tiryakian (1989), el modelo liberal en Sociología (Durkheim, Weber, Parsons) considera que aspectos centrales de la modernización del mundo son la racionalización, la diferenciación y las nuevas bases de integración solidaria que surgen de la interdependencia cooperativa y de los valores compartidos de la Modernidad, cuestiones que - para buena parte de la Sociología liberal- poco o nada tenían que ver con el nacionalismo.

Cierto es que autores como Durkheim desconfiaban de las relaciones sociales basadas únicamente en el interés, necesitando la fuerza cohesiva de las normas colectivas reconstituidas del tipo de sociedad «mecánico». Pero también lo es, como nos recuerda Smith (1971), que su actitud recelosa hacia el poder político y su explícita equiparación de «lo social» como los elementos morales y sagrados dificultaban el que éste proporcionara una explicación del nacionalismo.

Es igualmente cierto que, en los años sesenta (atiéndase, no obstante, a la avanzada fecha del logro), el «enfoque de la modernización» estudió el nacionalismo como vía para superar el abismo entre una comunidad premoderna y una sociedad basada en el cálculo del interés. Pero, además de simplificar la transición — como señalan autores como Smith (1971) o Breuilly (1982) - y de no sortear adecuadamente las críticas que desde fuera se hicieron a su propensión teleológica (Smith, 1971; Nisbet, 1970), el nacionalismo fue considerado útil en tanto en cuanto no se hubiera superado la «etapa de modernización». Una vez se accede al estadio de la Modernidad —suponen estos teóricos- desaparece el nacionalismo como objeto de estudio, como ya entonces había sucedido con el estudio del Estado-Nación occidental. 
Por su parte, el marxismo consideró que el nacionalismo tenía los días contados: no se trataba en este caso de la armonía resultante de la división internacional del trabajo, sino más bien del melting pot de la clase proletariada. Para el marxismo, en expresión de Gellner (1964), «los trabajadores anónimos, cuyo trabajo era una mercancía sobre la que se comerciaba, socialmente desheredados por las comunidades de las que formaron parte, desarraigados e impedidos por el sistema a forjar nuevas comunidades, no tenían nacionalidad» (trad. mía).

En definitiva, la razón sociológica se ha venido expresando - hasta hace un par de décadas - de manera poco favorable a conceder a la nación un lugar en el devenir de la Modernidad. El «progreso» de la historia hacía sospechar que el tiempo de las tribus, etnias y naciones iba a dar paso al «tiempo del internacionalismo». Aquél, pleno de supersticiosas tradiciones y oscuras creencias, sería derrotado por la fe racional de los hijos de la Ilustración. Ningún «espacio» social podía rebelarse a la expansión de la razón. Todo «lugar» sería devorado por una razón que era poseedora del único tiempo posible, el tiempo transfronterizo del progreso. Es cierto que la grandeza de los clásicos les hizo a menudo dudar de tal progreso, pero pocas veces articularon sus dudas en otros espacios comunitarios.

Dicho de otra forma (y utilizando de nuevo las variables espaciotemporales): la Sociología, como la Economía Política moderna, heredaba el supuesto de Marx de que el dinamismo capitalista implicaba la destrucción inevitable del «espacio» por el «tiempo»: «Todo lo sólido se desvanece en el aire», habían afirmado Marx y Engels en El Manifiesto Comunista Foucault (1980), refiriéndose a las Ciencias Sociales, afirma: «Se consideró el espacio como algo muerto, estático, contrario a la dialéctica, inmóvil. El tiempo, por otra parte, era sinónimo de riqueza, fecundidad, vida, dialéctica... El uso de términos espaciales parecía tener el aspecto de la antihistoria. Si uno empezaba a hablar en términos de espacio significaba que era hostil al tiempo. Quería decir (...) que uno "negaba la historia"..." (trad. mía).

\section{PSICOLOGIA SOCIAL DEL PREJUICIO: EL NACIONALISMO COMO ESPACIO PSICOLOGIZADO}

Si en el campo abonado por el racionalismo cartesiano y por la crítica ilustrada al Absolutismo - la Francia del siglo XVIII - era posible una explicación sociológica de las distorsiones del conocimiento, se entiende que con Helvétius, Holbach y Destutt de Tracy se pase del "prejuicio inconsciente — “idola" - al prejuicio interesado, a la mentira». La ampliación que de este nivel sociológico haría mucho más tarde el marxismo se diluye analíticamente a causa de las profecías históricas señaladas.

Por contra, las teorías psicosociales sobre el "prejuicio» se han situado mayoritariamente en el nivel de explicación psicológico. Admitiendo excepcio- 
nes - como las teorías funcionalistas de la interacción grupal (Sherif et al., 1961) o la teoría de la identidad social (Tajfel, 1981)_, lo cierto es que sólo hay que revisar tipologías como las de Ashmore y Del Boca (1976) para cerciorarse de la mayor tradición psicosocial en el «nivel individual» de análisis del prejuicio. (Para una revisión más pormenorizada, véase Ramírez, 1992).

Pudiera ser que al psicologismo aludido hubieran contribuido no sólo la inercia de la propia disciplina de la Psicología Social, anclada a menudo en una óptica que señala al individuo como su punto de partida (Correa et al., 1994), sino también la citada ausencia de una fuerte tradición sociológica de estudio del nacionalismo. Si la Sociología renuncia a ver en las naciones un campo de estudio necesario para dar cuenta de la Modernidad, a la Psicología Social sólo le queda trabajar su parcela como remanente de etnocentrismo individual.

Los estudios sobre autoritarismo y dogmatismo (Adorno et al., 1950; Rokeach, 1960; Altemeyer, 1981) conectan con la estructura motivacional y la estructura cognitiva del sujeto para explicar el prejuicio. Bien es verdad que el grupo de Adorno, por ejemplo, intentó relacionar la estructura del carácter con la estructura social (moderna) y que, como Wetherell y Potter (1992) advierten, la cadena de causas y efectos era compleja (hábitos, interacción con los padres, personalidad, ideología política, etc.) pero, en último término, cristalizaba en la debilidad del carácter del portador de prejuicios, en su rigidez cognitiva, sus necesidades emocionales o su evitación a nueva información.

Esta psicologización del prejuicio nacionalista conllevaba, además, una explicación del mismo en términos patológicos. El pensamiento prejuicioso es irredimiblemente dogmático e intolerante. Desprecia abiertamente a los exogrupos, al tiempo que se enorgullece irreflexivamente del grupo al que pertenece. Desde el ya clásico trabajo de Adorno (1950) hasta el bastante más reciente de Forbes (1986), la rigidez cognitiva del etnocentrista restringe su pensamiento a los supuestos de su propio endogrupo (nacional). Como afirma Levinson (1950), la ideología etnocéntrica "se basa en una insistente y rígida distinción entre endogrupo y exogrupo; incluye una imaginería de estereotipos negativos y actividades hostiles hacia los exogrupos, una imaginería de estereotipos positivos y actitudes sumisas en relación con el endogrupo, y un punto de vista jerárquico y autoritario de la interacción grupal en el que el endogrupo es privilegiadamente dominante y los exogrupos subordinados».

Por otra parte, que explicaciones válidas sólo puedan encontrarse precediendo los procesos comunicativos (cotidianos) de la Modernidad se adecúa bien al supuesto sociológico de que el nacionalismo tiene sus raíces en el pasado. También para este «enfoque irracional» sobre el prejuicio, cualquier «explicación científica» ha de remontarse a oscuros - y lejanos - orígenes, cualquier explicación sobre el etnocentrismo nacionalista debe conjugarse en pasado, dando cuenta de los conflictos emocionales no resueltos en la infancia.

Además de estas "coordenadas temporales», las «espaciales» no son menos importantes para entender esta perspectiva irracional del estudio del prejuicio. Así, el grupo de Adorno utiliza una "geometría espacial» (o diversidad de pla- 
nos en estudio) para diferenciar entre «lo superficial» («normatividad social sobre tolerancia») y "lo profundo» («motivación individual hacia el prejuicio»), entre el plano manifiesto de la comunicación y el plano escondido de la psique, entre lo externo y lo interno, higher y lower, "superficial» y "genuino». Tales divisiones no sólo impiden superar la sobrepsicologización del enfoque, impidiendo al tiempo una psicología social del nacionalismo basada en procesos de interacción comunicativa en el ámbito de la Modernidad, sino que, además, mantienen intacto uno de los supuestos más comúnmente sostenidos por la psicología social del prejuicio, el de la "consonancia cognitiva». En efecto, y con independencia de la causa que lo origine, hay siempre una tentación a asumir una consonancia cognitiva individual subyacente, que conlleva - además_ una delimitación social entre «amigos» y «enemigos» del nacionalismo.

Pudiera ser que esta idea de «consonancia cognitiva» fuera uno de los pocos supuestos comunes al enfoque irracional y al cognitivo del estudio del prejuicio. Ahora bien, para la psicología cognitiva, el «prejuicio» necesitaría de una aproximación mucho más inclusiva que la apuntada por los clásicos estudios sobre etnocentrismo. La mente humana — se postularía desde la perspectiva de la cognición social- es limitada, y requiere del proceso de "categorización». Como afirman Cantor et al. (1982), los esquemas de categorización nos permiten estructurar y dar coherencia a nuestro conocimiento general sobre la sociedad, suministrándonos expectativas sobre tipos de conducta y variación entre tipos de personas. Aquí ya no estaríamos estudiando el "prejuicio» (nacionalista) para dar cuenta de los comportamientos ausentes del modelo racional y tolerante de la filosofía postilustrada, sino como variante del modo más común de categorización social. De hecho, como apunta Billig (1987), «la persona como un categorizador de información puede ser comparada a un individuo prejuicioso cuyos errores provienen de su irreflexión intolerante, o a un burócrata que busca poco más que rutinas bien ordenadas». (Billig excluye conscientemente la metáfora utilizada por la teoría de la atribución causal.)

Estereotipar al exogrupo es, de este modo, un ejemplo de proceso cognitivo normal. "Man has a propensity to prejudice», había afirmado ya G. Allport en 1958. No debiera subestimarse la importancia potencial que la perspectiva de la cognición social —basada en procesos de "estereotipia» y "categorización»- podría tener en el campo de estudio de naciones y nacionalismos. Sin embargo, las premisas psicologistas y ahistóricas de la cognición social son difícilmente articulables con los procesos sociohistóricos e ideológicos que explican la evolución diacrónica del nacionalismo. Por ejemplo, en cuanto a su psicologismo, este enfoque asumiría que el proceso de categorización (y, por tanto, el prejuicio nacionalista) tiene lugar dentro de la mente individual (Wetherell y Potter, 1992) y no a partir de procesos de comunicación social intra e internacionales.

El carácter formalista de la investigación psicosocial, con su afán descontextualizador, potencia la dimensión ahistórica del enfoque cognitivo: la investigación tradicional sobre estereotipos (nacionales o raciales) asume que los 
sujetos analizados están reaccionando a un «único» objeto de estímulo, como ha sido recientemente criticado (Potter y Wetherell, 1987; Billig, 1991; Somers y Gibson, 1994). Además, y en relación con esto, se supone que, aunque el sujeto manifieste ambivalencia congnitiva hacia determinado objeto de estímulo, tal ambivalencia esconde — en el fondo- una "consonancia cognitiva» subyacente. Aquí de nuevo es necesario tener presente la centralidad de la "categorización» - como propensión natural humana- en el marco explicativo de la cognición social: «Es la imagen del intolerante cuya mente sólo atiende a lo que confirma la idea fija que está en la base de su intolerancia», afirma Billig (1987).

\section{LAS FRONTERAS CATEGORIALES DE LA MODERNIDAD: EL NACIONALISMO COMO ESPACIO IDEOLOGICO}

Las fronteras (políticas) de la Modernidad nos proporcionan el contexto sociohistórico que a la idea de "categorización» le falta en la perspectiva — psicologizante - de la cognición social. La lógica —en buena medida contradictoria- de su existencia social y sus correlatos en la conciencia espacial del hombre contemporáneo hacen de ellas un punto de arranque privilegiado para el estudio de las identidades nacionales y los nacionalismos.

Las fronteras modernas han sido - por lo tanto- espacios definidos de exclusión e inclusión. Han sido más cosas. Pero también esto, sin duda alguna. Delimitaciones precisas e identificables en la línea del horizonte. Barreras trazadas a escuadra que marcan la separación con «lo extranjero». Metáforas de la lógica categorial (del enfoque cognitivo) hechas realidad. (Pura encarnación de semejante acepción de "prejuicio».) Es ésta una cuestión importante. No se trata sólo de las consecuencias que tales «barreras» físicas conllevan, sino sus efectos en la imaginación del hombre moderno.

No siempre fue así. Hubo que esperar — al menos— la aparición del «principio de soberanía del Estado» (Maquiavelo, Bodino, Hobbes) para imaginar sobre la superficie de la Modernidad la lógica categorial de unas fronteras precisas e identificables. Para Walker (1993), los constructos espaciales asociados con Euclides - la geometría de los espacios homogéneos- jugaron un papel decisivo en determinar las formas culturales de la civilización europea, como es evidente en la pintura italiana de finales del siglo XV y principios del XVI (the one-point perspective system) o en la revolución cartográfica que acompañó la expansión del comercio por la superficie terrestre. En este contexto intelectual e histórico — afirma Walker - se produjo en la Europa postrenacentista la emergencia del vínculo entre la idea de soberanía del Estado y una concepción de espacio claramente delimitado e inviolable.

Fue así como las frontiers - vagas y disputadas - se convirtieron poco a poco en borders - precisas e identificables- (Giddens, 1987). De este modo pasamos, tomando prestado el símil gellneriano, de un espacio global que 
semeja un cuadro de Kokoschka («la explosión de los diferentes puntos de color es tal que no se puede discernir con claridad ninguna forma definida, aunque el cuadro como un todo sí la tenga. Una gran diversidad, pluralidad y complejidad caracteriza las distintas partes del todo") a uno pintado por Modigliani («hay muy pocas sombras; superficies lisas y ordenadas se separan claramente, por regla general está claro dónde empieza una y termina la otra, y hay poca ambigüedad o superposición, si es que la hay»).

Ha sido Benedict Anderson uno de los autores que mayor insistencia ha hecho en los efectos categorizadores de la tecnologización del mundo. El nos muestra, por ejemplo, cómo a la revolución astronómica y cartográfica —que dibujara una línea precisa en los espacios horizontales de la Modernidad- le siguió, siglos más tarde, la interacción con los beneficios que el capital podría obtener de la imprenta y la fotografía. Esto posibilitó la utilización generalizada de mapas replicables y una nueva contribución a la representación cotidiana de los espacios euclídeos de la Modernidad.

Algo había cambiado igualmente en la elaboración de los mapas, pues el ojo del dibujante en épocas anteriores se había situado a la misma altura del suelo. A juicio de Anderson, la mayor parte de mapas premodernos no eran sino cosmografías de carácter religioso o guías para campañas militares y labores de subsistencia que implicaban algún tipo de desplazamiento. Mientras las primeras mostraban una disposición vertical (en el eje que unía el cielo y el infierno), las segundas eran dibujadas en una curiosa perspectiva oblicua (como si los ojos del dibujante, acostumbrados a situarse en su hábitat, fueran, sin embargo, subliminalmente influidos por la verticalidad de la cosmografía). Frente a tales formas de representar el mundo, la horizontalidad de nuestros mapas contemporáneos y la precisión de su trazo ejemplifica la lógica categorial con la que la nación se imagina a sí misma (y a la alteridad).

Ahora bien, semejante categorización agotaría nuestro análisis sólo si limitamos la funcionalidad de los mapas modernos a los trazos fronterizos. Sin embargo, la revolución cartográfica fue de la mano de la revolución astronómica y de los avances técnicos de la navegación, y ambas contribuyeron directamente - como no podía ser de otra manera- a la realización de los «grandes viajes» en los albores de la Modernidad. Los orígenes del Estado-Nación coinciden en el tiempo con los del sistema-mundo (Wallerstein, 1988). Las fronteras — precisas e identificables — son al tiempo sitios de paso progresivamente transitados.

Por eso, no bastará ya con decir que para la aparición de la nación es suficiente la existencia de un "Otro» que la nueva frontera claramente discrimina. "Saber que hay un otro", "conocer a ese otro", "conocer lo que ese otro cree conocer de mím son grados diferentes de acercamiento a la alteridad (Lamo de Espinosa, 1993). Lo fundamental podría ser, en consecuencia, entender el modo específico en que estas comunidades nacionales se imaginan a sí mismas e imaginan al Otro, esto es, el modo distintivo en que las naciones imaginan comunidad. 
Sólo así nos aproximamos al componente ideológico del nacionalismo. Autores como Dumont (1982) o Calhoun (1993; 1994) han afirmado que el supuesto cultural más decisivo para entender la existencia de las identidades nacionales es la concepción moderna de "individuo" como ser autosuficiente y autocontenido. La naturaleza categórica de la frontera, su invitación implícita a las propuestas de normalización y pureza cultural o étnica, tendría su correlato socioideológico en el homo clausus elisiano.

Esta superposición ideológica hace que la nación - como colectivo social - no sea entendida como una red de relaciones entre personas o jerarquías sociales, sino más bien como una "categoría» de sujetos equivalentes (Dumont, 1982; Calhoun, 1991; 1993; Segal y Handler, 1992). Por tanto, no sería contradictoria la afirmación de que una ideología sobre colectividades («nacionalismo») fuera una variedad del individualismo moderno.

De este modo, las naciones son a menudo vistas como equivalentes lógicos a semejanza de individuos (Calhoun, 1993). Por ejemplo, la teoría internacional liberal sugiere que una nación como San Marino es formalmente equivalente a una nación como China. Otras veces las naciones se representan con rasgos antropomórficos, como si ellas mismas tuvieran vida. En expresión de Anderson (1991), "the idea of a sociological organism moving calendrically through homogeous, empty time is a precise analogue of the idea of the nation, which also is conceived as a solid community moving steedily down (or up) history».

\section{TAJFEL Y ELIAS: ENTRE LA AMBIVALENCIA SOCIOLOGICA Y LA INTERNALIZACION PSICOLOGICA}

Como hemos visto, el prejuicio (nacionalista) no es necesariamente un remanente del etnocentrismo del "pasado» ni un fenómeno que únicamente requiera de un «nivel individual» de explicación. Más bien, la categorización (nacional) tiene que ver con los efectos que la tecnologización del mundo tiene en la conciencia espacial del sujeto. Es asunto tan «moderno» como el trazado - preciso e identificable - de las fronteras políticas de los Estados soberanos, afectando su juego de inclusiones y exclusiones a la identidad colectiva de los «grupos» implicados. Todo ello tiene lugar en el contexto de un sistema-mundo emergente. Esta es, sin duda, la gran paradoja de la frontera moderna: la dificultad de entender el nacionalismo fuera del marco temporal del internacionalismo.

Decir que el nacionalismo es una variante del individualismo ideológico (Dumont, 1982; Calhoun, 1993, 1994) es anclar al sujeto en sucesivos círculos (o fronteras) concéntricos donde lo primero a resaltar es la lógica categorial que hace posibles unidades individualizadas (a cualquier nivel de análisis que nos situemos). En semejante cascada de categorías ideológicas — en la que aparece incesante el reflejo del homo clausus_, lo más difícil podría ser la com- 
prensión sociológica y psicosocial de la coexistencia temporal de los diferentes niveles.

Tajfel $^{2}$ (1981) se pregunta qué contexto social es necesario para que un sujeto se comporte en términos «intergrupales» y cuál para que lo haga en términos «interindividuales». La teoría de la identidad social de Tajfel no parte del esquema de círculos concéntricos —especificado arriba-, sino del supuesto de que todo encuentro social puede localizarse en algún lugar de un continuum cuyos extremos lo forman la conducta puramente «intergrupal» («conducta determinada por la membrecía grupal de los participantes») y la conducta «interpersonal» («interacción determinada por las relaciones personales entre los sujetos participantes y por sus características individuales respectivas»). Según esto, nacionalismo e individualismo requerirán contextos sociales diferentes, pues a medida que nos acercamos a un extremo del continuum nos alejamos inevitablemente del otro.

Lo importante para Tajfel no es sólo buscar explicaciones del "prejuicio» (nacionalista) en términos de procesos psicológicos — como hacía la psicología cognitiva-, sino buscarlas igualmente en el contexto sociológico que posibilita conductas cercanas al polo «intergrupal» de su continuum. Este es el extremo en que se gestan —según él- los procesos de categorización y prejuicio (nacionalista). La identidad nacional, a su vez, sería — para Tajfel_ precipitado de este proceso de categorización: la identidad de todo grupo (nacional) procedería de la "comparación» y la «diferenciación» con los grupos circundantes (de la sociedad internacional). Por lo tanto, las características de una nación (su status, su riqueza o pobreza, su color de piel o su habilidad para alcanzar sus metas) adquieren significado para los nacionales sólo en relación a percibidas diferencias con otras naciones y a las connotaciones de valor de tales diferencias.

Pero ¿cuáles son las condiciones sociales señaladas por Tajfel para el surgimiento de conducta «intergrupal»? La condición básica para la aparición de conductas cercanas al polo «intergrupal» del continuum es la creencia en que las fronteras sociales relevantes entre los grupos están delimitadas con precisión e imposibilitan, sea cual sea la causa, la movilidad de los individuos de un grupo a otro.

Claro que si, como afirman las teorías de la comparación social o la teoría de la deprivación relativa, la "comparación» es sólo posible en supuestos de "similitud subjetiva», ¿por qué habrían de "compararse» grupos (nacionales) para los que la movilidad de uno a otro está imposibilitada por la lógica impenetrable de las fronteras? Aquí el concepto de «legitimidad» es central o, mejor dicho, lo son las condiciones históricas y sociales que posibilitan el concepto de legitimidad. Tajfel afirma que en un medio social en proceso constante de cambio, como es el contemporáneo, no se debe pasar por alto la fuerza expan-

2 Para una discusión teórica — más elaborada — de la teoría de la identidad social de Tajfel en su aplicación potencial en el estudio del nacionalismo, véase Ramírez (1989). 
siva que principios genéricamente aceptados (como el de «todos los seres humanos somos iguales») tienen en el desarrollo potencial de nuevas dimensiones de "comparabilidad» (o subyacente similitud) donde antes no existían.

Ahora bien, si la lógica de la categorización de las fronteras de la Modernidad se asienta sobre principios universalistas, no basta con «saber que hay un Otro" (o discriminar) para entender el modo en que la nación imagina comunidad. Cuanto menos habrá que tener — también- en cuenta que el nacionalista "conoce a ese Otro». Sólo así se podría creer — como hace Tajfel— en la existencia de una «similitud subyacente».

Lo fundamental es que Tajfel — sin saberlo- rompe en este punto con el continuum del que partió, pues si el principio ilustrado según el cual «todos los seres humanos somos iguales» hace posible múltiples dimensiones de comparabilidad «intergrupal», el contexto sociológico que posibilita cada uno de los tipos del continuum es en este caso el mismo, con el resultado de que los extremos ahora se tocan. Un entorno «internacionalista» lleva -implícito- nuevas posibilidades para una futura conducta "nacionalista». Y viceversa: un contexto social proclive al nacionalismo, en el marco de una sociedad de cambio acelerado, conlleva — de nuevo, de modo implícito- procesos de internacionalización intragrupal.

No estará de más recordar el importante cambio experimentado a estas alturas por el concepto de "prejuicio». Si todavía Adorno et al. dicotomizaron "prejuicio»y "razón», haciendo portador a éste de las esperanzas del futuro, mientras que aquél cargaba con el pesado lastre de un pasado afectivo insuficiente (transmutado — periódicamente- en comportamientos nacionalistas y racistas), Tajfel resitúa a ambos — «prejuicio» y «razón»— en el mismo plano imaginario, haciendo a la razón principal garante del acceso al marco de la Modernidad de una multitud de nuevas dimensiones de comparabilidad colectiva, generadoras a su vez de diferentes "espacios» para el prejuicio grupal. Como afirma Tajfel: "Vivimos en un mundo en el que los procesos de unificación y diversificación proceden aprisa, ambos a un ritmo más acelerado que en cualquier momento histórico anterior. En cierto modo los grupos humanos a gran escala se comunican recíprocamente más que nunca (...) y son progresivamente interdependientes. A la vez, hay una poderosa tendencia (...) pretendiendo preservar los logros de la diversidad, las características particulares de uno mismo y la identidad (...)» (trad. mía).

La dialéctica de la categorización cognitiva ("compararse-diferenciarse») se enmarca, así, en el proceso de «unificación-diversificación» a nivel social.

Tajfel interpreta la plausibilidad social de ambos procesos («unificacióndiversificación») en los espacios de la Modernidad. Pero no nos resuelve el enigma de los círculos (o fronteras) concéntricos, pues mientras es consciente de la coexistencia —-sociológica — de las tendencias aludidas, sigue encerrando al sujeto en la cárcel (cognitiva) de la categorización: el sujeto — según Tajfel- sólo puede estar en un enclave espacial del continuum, bien en el bando de los nacionalistas, bien en el de los internacionalistas; bien reivindicando «la 
diferencia» (y, en consecuencia, comportándose «intergrupalmente»), bien asumiendo los rasgos comunes a la Humanidad entera (e interactuando a nivel «interindividual»). Prejuicio (nacional) y razón (cosmopolita) son, en última instancia, separados a nivel individual, a pesar de la creciente ambivalencia sociológica de los espacios — tecnológicos— de la Modernidad (expansión de la cadencia "comparación-diferenciación»). Los círculos — para Tajfel— no tienen el mismo centro. La cuestión del nacionalismo - de nuevo- deviene marginal a la propia Modernidad.

Aunque Tajfel comprenda la complejidad cognitiva de los viajes de la Modernidad, el prejuicio es —otra vez- psicologizado. El proceso de categorización o estereotipia sigue residiendo en el «interior» del individuo (y la discriminación es la resultante de su externalización). Los grupos sociales son - a su vez - concebidos como ya existentes y predefinidos.

Pudiera ser que el autor estuviera asumiendo una versión sobreideologizada del individuo (y del grupo), que es precisamente la que debe ser explicada para entender la coexistencia de nacionalismo e internacionalismo. Por eso, para Tajfel, el prejuicio (y la discriminación) se conducen "de dentro a fuera» (del interior del individuo a su externalización): la acción — se asume- está controlada por un sistema integrado de características de su personalidad y de creencias consistentes interiorizadas. Esta filosofía del individuo - como afirman Wetherell y Potter (1992) — está en deuda con el individualismo manifiesto en las tradiciones de pensamiento liberal (Hall, 1986) y, a un nivel superior -el del grupo o el de la nación-, con la concepción de los espacios euclídeos de la Modernidad (lo que Walker asemeja a la sátira de Swift, Los viajes de Gulliver).

Otros autores arrojan luz a las categorías ideológicas aludidas (individuo y grupo) al abordarlas de entrada a partir de las «relaciones sociales» de la Modernidad, esto es, dentro de un contexto (ampliado) de redes complejas de relaciones sociales (Burkitt, 1994). Así, Norbert Elias piensa que es la experiencia cambiante de individuos (y estratos sociales) en un entorno social de fronteras ambivalentes con «los otros» lo que habría que considerar. Según él, hay "una especial cualidad de las relaciones humanas que también fue surgiendo con la creciente división de las funciones en la sociedad: "su abierta o latente ambivalencia”. Tanto en las relaciones interindividuales como en las relaciones entre diferentes estratos funcionales, se manifiesta una específica "dualidad o incluso multiplicidad de intereses" de forma tanto más marcada cuanto más amplia y densa sea la red de interdependencias. En tal caso, todo el mundo, todos los grupos, estamentos o clases dependen en cierta medida los unos de los otros: son amigos, aliados o compañeros potenciales; y son al mismo tiempo oponentes, competidores y enemigos potenciales» (Elias, 1982).

Para Elias, este contexto de «ambivalencia» (fronteriza) con el otro exige del sujeto una mayor capacidad de "previsión" para planear y coordinar actividades conjuntas. A su vez, la necesidad de escrutar la conducta ajena conduce 
a un aumento de la reflexividad por parte del actor, esto es, una capacidad creciente de "verse a sí mismo desde el otro". Nace con ello el discurso categorial sobre el self.

Ahora bien, en Elias este marco de relaciones ambivalentes que implican una mayor contención en la reacción frente al otro conduce — de nuevo- a la noción de internalización (ahora en versión freudiana) y a la noción de hábito. Por ello no es casual que, para Elias la ambivalencia tenga su lugar originario en los espacios no ya delimitados (como las fronteras), sino cerrados (como la Corte), y expandido con la creciente incorporación de los convidados a la mesa de la "civilización». La concepción de una trama - creciente- de sujetos interdependientes que reflexionan en el plano horizontal de la Modernidad a partir de las fronteras ambivalentes que les unen/separan coexiste con la concepción moderna del Estado como depositario exclusivo de la supervivencia seguridad frente al enemigo y provisión de recursos materiales.

De este modo, en el entorno de la Corte o - como diría A. de Swaan (1995) - en los círculos territoriales de identificación que se amplían progresivamente a partir de ella (widening circles of identification) se recupera la sustancia femenina de la nación (de la tierra madre, del hogar y de la mesa) y la sustancia paterna (la defensa frente a «lo extraño»). Elias nos muestra los espacios horizontales de la Modernidad (redes ampliadas y ambivalentes de sujetos y grupos interdependientes), pero un ojo estrábico se pierde junto a la mirada — vertical — de Narciso. La idealización de las categorías propias, el rechazo de los rasgos inaceptables en los (diversos) círculos de pertenencia, la proyección de tales características en los Otros: todo ello tiene lugar en el proceso de formación de identificaciones del yo (I-identifications) e identificaciones del "nosotros» (we-identifications), siempre como una dialéctica de inclusión y exclusión. (Véase Stein, 1990; Mennell, 1994; De Swaan, 1995.)

Si en Tajfel era el concepto de "categorización» — aún anclado en el individualismo de la psicología cognitiva-, en Elias es la noción psicoanalítica de «identificación» (y proyección) la que nos conduce de nuevo a la idea de «interiorización». Freud (1964) utilizó la expresión "narcisismo de diferencias menores» para describir la intensa hostilidad mutua que la vecindad o la gran similitud despertaba entre las naciones. Para él era una manera de mantener separada la identidad de cada una de ellas. La noción psicoanalítica de «interiorización» —utilizada también profusamente por los teóricos de la modernización- dificulta, sin embargo, la explicación de la coexistencia de las diferentes fronteras concéntricas de la Modernidad.

\section{LA MODERNIDAD, LA CONTINGENCIA ESPACIAL Y LA RETORICA DEL ESTADO}

El discurso (categorial) sobre el self conecta — dice Elias (1991) — con la cambiante experiencia del individuo dentro de un contexto ampliado de redes 
dinámicas de interacción social. Es la «desterritorialización del espacio» (Mlinar, 1992), la creciente complejidad de las relaciones sociales de nuestro mundo contemporáneo, lo que devuelve el espejo roto de la propia identidad $y$, por tanto, el discurso moderno que socialmente la reivindica.

El sujeto se ha de ver desde el otro si quiere prever las consecuencias sociales de su acción. Tal imperativo no es nuevo, pero sí lo es la problematización creciente de dichas consecuencias: la heterorreflexividad se desliza por el plano horizontal de la Modernidad, deslegitimando la tradición y permitiendo la secularización de la vida. Es así como los procesos de industrialización, urbanización, los avances en la capacidad de comunicación y, en general, la densa y ampliada red de interdependencias de nuestras sociedades contemporáneas coexisten - necesariamente- con el discurso categorial sobre el self. Los inicios de la mundialización de los espacios van de la mano del individualismo ideológico (tanto al nivel del sujeto como al de los grupos implicados).

Por eso, los teóricos de la modernización sólo aciertan a capturar una dimensión de los procesos implicados en la construcción del Estado. Para ellos, la lógica de la modernización social y política conlleva que las unidades espaciales de tamaño reducido — por ejemplo, aldeas, pueblos, ciudades, regiones - pierdan cada vez más autonomía en relación a la unidad de nivel superior, el Estado. Qué duda cabe que la coacción centralista fue a menudo utilizada en la transformación del campesinado en "ciudadanía» (E. Weber, 1976) - tanto más coactiva cuanto más nos acercamos a las primeras etapas de la modernización (Mlinar, 1992) - . Pero no se debe olvidar que tales procesos de globalización del espacio conllevaron a menudo el aumento del individualismo de los niveles inferiores de adscripción, al ser capaces de verse a sí mismos desde el nivel inmediatamente superior.

Podría pensarse que la ambivalencia fue tal en tanto estaba referida a sujetos y grupos sociales inmersos en la construcción del Estado moderno, perdiéndose en cambio en la frontera (política) que separaba del Otro, del extranjero. Sin embargo, quizá no sea fortuito que la obra de Fichte se considere fundamental para entender — a un tiempo- la aparición del «individualismo» y el «nacionalismo». Para Fichte, la noción del autorreconocimiento individual (la persona que, poniéndose frente al espejo, dice "yo soy yo») está inseparablemente unida a la idea de nación como individuo (Calhoun, 1994). Del mismo modo, Herder aplicó al mismo tiempo su concepción de originalidad a dos niveles diferentes, el de la persona individual y el del «pueblo» o Volk como portador de una determinada cultura, irrepetible expresión de humanidad (Taylor, 1992).

Según esto, no habría incompatibilidad entre internacionalismo (o globalización) y nacionalismo (que — según vimos- puede considerarse una derivación del individualismo). Todo lo contrario: sólo explicando su coexistencia tiene sentido su juego categorial, pues sólo viéndonos desde el Otro podemos siquiera plantearnos el «ideal de autenticidad» (Taylor, 1992) que la problematicidad de la propia autonomía genera. Por eso, el narcisismo nacionalista 
— del que Freud hablara- puede «imaginarse» de manera diferente. Como afirma Billig (1992), Narciso ha cambiado: sigue mirando su propia imagen reflejada en la fuente, pero las aguas han dejado su anterior estado cristalino. Sabe, por tanto, que su propio reflejo puede engañarle, por bello que pueda ser. Inclinado sobre el borde de la fuente, él ve algo más: son los ojos de las otras naciones que le contemplan desde el agua con actitud ambivalente.

El estudio del nacionalismo no puede limitarse a la órbita de «comunidades culturales», "territorios», "hábitos de lenguaje y pensamiento» o "memorias de infancia» (Deutsch, 1953). Su análisis debe atender a la interacción —contradictoria- de "tecnología» y "conciencia» sobre los planos horizontales de la Modernidad. Es preciso, por eso, retornar a los espacios contingentes de la "civilización», pero ahora sobre la superficie del «mapa»: el nacionalismo no se constituyó en el ámbito — cerrado- de la Corte, sino en la distancia — cartografiada - entre unas cortes y otras. La ambivalencia cruzó la frontera del Estado.

Ampliado de este modo el ámbito social de la ambivalencia — más allá de los ángulos alumbrados por Elias-, la cuestión de la incompatibilidad de las frontras concéntricas que conforman la identidad del individuo moderno se nos aparece bajo una luz diferente. Como señalamos, las Ciencias Sociales han concebido tradicionalmente el nacionalismo en términos de oposición radical al internacionalismo ("as a tug of war between reason and passion», había apuntado Gellner ya en 1964). La misma oposición se ha presentado con diferentes pares dicotómicos: razón versus prejuicio, cosmopolitismo versus nacionalismo, supranacionalismo versus endogrupalidad, razón versus pasión... En buena medida, tal aproximación adquiere renovado impulso cada vez que las Ciencias Sociales anuncian la (inminente) muerte del nacionalismo. Los Estados — se afirma - tienen enormes problemas para controlar los mercados globales, las corporaciones multinacionales, los flujos migratorios a gran escala o la «subgrupalidad» (Rosenau, 1990).

Ahora bien — como advierte Calhoun (1994)—, estos analistas pocas veces consideran la posibilidad de que, más que anunciar la muerte del nacionalismo, todas estas tendencias y dificultades son precisamente su razón de ser. «El nacionalismo — afirma Calhoun - es la retórica de la identidad y solidaridad con la que los ciudadanos del mundo moderno más prontamente tratan con la naturaleza problemática del poder del Estado y con cuestiones relacionadas de inclusión y exclusión. Más que acompañar la construcción del Estado en total correlación, el nacionalismo es casi siempre un problema allí donde las fronteras y el poder del Estado no coinciden con la voluntad de sus miembros, o la escala de acción emprendida por otros actores colectivos» (trad. mía). 


\section{LOS PREJUICIOS DEL INTERNACIONALISMO}

De este modo, «globalización»e «individualización», «internacionalismo»y «nacionalismo» son procesos coetáneos. A medida que las fronteras desaparecen y se reduce el número de entidades políticas aisladas, tiene lugar una tendencia opuesta hacia la «individualización» de los subsistemas espaciales implicados en aquel proceso (sean comunidades imaginadas, grupos o individuos), o lo que Mlinar (1992) denomina la «interiorización de las fronteras». Estos subsistemas asumen ahora cierta autoridad sobre sus «asuntos exteriores» (external affairs). De nuevo, esto ocurre tanto a nivel de unidades espaciales menores - lo que Blau (1977) llama la penetración de la diferenciación en las subestructuras- como a nivel individual (lo que se traduce en una creciente reflexividad del sujeto).

A nivel del individuo, la suposición de que el sujeto interioriza las fronteras de la Modernidad no es sino un artificio lingüístico válido para acercarnos al estudio del prejuicio (nacionalista). El hombre es «retórico» — nos recuerda Billig (1987) — porque es capaz de ir hasta el alter y justificar la posición de éste. Sólo es posible el pensamiento cuando se dan estos dos elementos: un «espacio" mental escindido en dos fases temporales (lo que Peirce llamaba el $I$ y el you) y, al mismo tiempo, la posibilidad de atravesar recurrentemente la barrera entre una y otra. Frente al self de la psicología cognitiva, unitario y monológico, el self retórico ha de cruzar la frontera que le separa de alter, no sólo en ámbitos de público debate, sino en deliberaciones privadas. No obstante, no son estas deliberaciones, sino aquellos debates, los prioritarios para entender esta noción de self: el pensamiento se asienta en el plano horizontal de la interacción (Wiley, 1994). El reino del pensamiento es - sobre todo- el reino de la «justificación» y de la «crítica pública» (Billig, 1987; Crespo, 1995).

El nacionalismo sólo es posible cuando este viaje retórico deja de realizarse de forma prioritaria con un alter exhumado por la tradición endogrupal (y la consiguiente devolución — diría Giddens, 1993- del futuro al pasado) y comienza a serlo fundamentalmente con un alter "extraño» y lejano (que proyecta «la historia endogrupal» como narrativa incierta). La «justificación» y la "crítica» de cualquier argumentación sobre identidades se realiza sobre un espacio «desterritorializado» (Mlinar, 1992), esto es, teniendo en cuenta las múltiples fronteras concéntricas del self coexistentes en el plano horizontal de interacción, desde el municipio a la comunidad internacional. De este modo, cualquier reivindicación (en el polo intergrupal) nacionalista habrá de tener en cuenta, por ejemplo, la afirmación (internacionalista) de que «todos los hombres somos iguales» (Billig, 1991).

Para el self de la retórica nacional, las fronteras (políticas) de la Modernidad, las delimitaciones precisas e identificables en la línea del horizonte se aparecen ahora de modo diferente. Criticando a Tajfel, Wetherell y Potter (1992) afirman que la "categorización social», aun pudiendo considerarse un evento mental, es también parte de un entorno argumentativo de debate público. Por 
eso, cada dimensión de distinción es también apta —al menos, tácitamentepara establecer "comunalidad" con un Otro similarmente distinguido. Taylor (1992), si bien desde una óptica más moral que cognitiva, coincide con nosotros: no hay "diferencia» que no dependa en último término de común «reconocimiento".

Quizá por eso en investigaciones psicosociales sobre "prejuicios», realizadas a partir del análisis discursivo, posturas poco comprensivas hacia el emigrante a menudo tienen una estructura gramatical semejante a ésta: "I'm not prejudiced, but...» (Billig, 1991). Esta y otras locuciones semejantes, compuestas de complejas estructuras de condicionales, adversativas y contrastes, podrían implicar no tanto sucesivos actos de goffmaniana ocultación de motivos (geometría espacial), sino un conflicto social subjetivamente interiorizado a partir de una prolongada vivencia de las coordenadas espaciales de la Modernidad. Además, tales locuciones nos recuerdan que, más que interiorizar hábitos (Elias), el nacionalismo necesita para subsistir de la interiorización de fronteras (Mlinar), los repertorios discursivos para incluir y excluir — a un tiempo- «lo extranjero».

Todo ello resulta más comprensible si nos movemos con una noción gramsciana de sujeto estructurado por diversas ideologías implícitas en sus prácticas y, por tanto, poseedor de un carácter "extrañamente compuesto". Esto es, una visión del "sentido común» como almacén complejo y heterogéneo de luchas ideológicas del pasado. Billig se sirve de una noción similar de sujeto en lo que él llama "dilemas de sentido común».

Esta concepción de «individuo» proporciona un punto de partida propicio para articular teóricamente los dilemas espaciales de sentido común con la noción bajtiana de intertextualidad (toda declaración está poblada con otras declaraciones), o la noción de "significado actitudinal implícito" de Billig (las actitudes no deben ser examinadas aisladas de su contexto retórico), y, en definitiva, nos ofrece una visión más adecuada del sujeto para explicar su papel en la dialéctica moderna de las coordenadas de espacio ${ }^{3}$. Abordando la cuestión de tal forma, nos libramos de la dificultad que el supuesto psicosocial de "consonancia cognitiva» tenía como elemento explicativo de la evolución de las identidades nacionales y del devenir cambiante y complejo del inter(-)nacionalismo. Por eso es importante señalar la "dimensión implícita» de las actitudes inter-nacionales. Más que esconder a un sinvergüenza — como afirmara el clá-

3 Sin duda, estoy en deuda con el profesor Eduardo Crespo por introducirme en planteamientos psicosociológicos que propugnan una nueva psicología social cognitiva a partir de un desplazamiento «desde un modelo intrapersonal del conocimiento (...) hacia un modelo interpersonal, en el que los procesos cognitivos se abordan en su faceta relacional, como actividad social» (Crespo, 1995). Este proceso — como indica Crespo- sigue los pasos del pensamiento filosófico y social más contemporáneo, pero también la recuperación de algunos clásicos de la Psicología Social, como G. H. Mead. Los procesos cognitivos entendidos como actividad social vuelven a plantear la legitimidad de una Psicología Social centrada en los procesos de «interacción simbólica» (Torregrosa, 1983 y 1984). 
sico-, lo que aquí he pretendido sugerir es que todo nacionalista esconde detrás un internacionalista, y viceversa.

Y no apunta esto a un problema secundario en el devenir moderno de las «identidades espaciales». De hecho, una de las cuestiones que mayor perplejidad ha producido a los estudiosos del "prejuicio" ha sido la de cómo explicar los repentinos cambios en el aumento (y disminución) de los prejuicios internacionales. El ejemplo clásico es, sin duda, el de la Alemania nazi, pero no ha dejado de ser asunto de actualidad, presente hoy, por ejemplo, en los ritmos cambiantes que el proceso de "construcción europea» experimenta. Al legar de las Ciencias Sociales la sinonimia de nación y antimodernidad, los prejuicios (nacionalistas) sólo se podían buscar detrás de cortinas de humo, bajo consciencias y disfraces, o en oscuras motivaciones y deseos latentes. Nunca en procesos comunicativos de la Modernidad, esto es, a ras del suelo, sobre la superficie, en la misma planicie en que se generaran, primero, los grandes viajes (inciertos y aventurados) de la Modernidad cosmopolita; después, los espacios cerrados de una Tierra circunvalada que originó la lógica intergrupal del nacionalismo; por fin, la multiplicación y generalización de las comunicaciones y la conversión — sobre todo en nuestro siglo- de cualquier lugar en un espacio fronterizo.

Sin embargo, en este peculiar tablero de la Modernidad, en este juego de planicie y meandro, homogeneidad y diversidad, comparación y diferenciación, se mueve con toda «legitimidad» la ambivalencia espacial del hombre de nuestro tiempo.

De todo lo anterior se podría deducir tentativamente que la «identidad nacional» es la gramática moderna que una comunidad imaginada construye colectivamente desde un espacio fronterizo para repensar su tiempo histórico en la era de la mundialización de las comunicaciones. Por eso, los autoestereotipos nacionales no son (sólo) categorías sociales usadas por individuos prejuiciosos que rutinizan el conocimiento general sobre su propia nación, ni una actitud individual hacia un simple objeto de estímulo (descontextualizado), sino (sobre todo) categorías dilemáticas (re)creadas desde un espacio comunitario sometido a las periódicas tendencias hacia el internacionalismo y la endogrupalidad.

O, dicho de otra forma: si bien la formación de los autoestereotipos nacionales son ampliamente variables en función del modo, el lugar y el tiempo en que una determinada "nación» accedió a la era de los espacios contingentes, deberán al menos cumplir una condición genérica, que es la de su dilematicidad o dialogismo. Y es que deberán justificar al mismo tiempo tanto el camino a la sociedad internacional como la vuelta a las (modernas) raíces comunitarias, tanto la invocación del futuro como la huida al pasado (véase Schwartz, 1990). 
Quizá por eso, los arquetipos cervantinos han quedado instalados como accesible gramática de nuestra memoria colectiva: no porque hoy -o hace cuatrocientos años - pudiera representar alguno de ellos (bien don Quijote, bien Sancho Panza) los valores cotidianos de nuestro mundo hispánico, sino porque don Quijote y Sancho Panza, cabalgando juntos, cabalgan en realidad — como la Modernidad- en sentidos opuestos.

\section{BIBLIOGRAFIA}

Adorno, T. W.; Frenkel-Brunswik, E.; Levinson, D. J., y SAnford, R. N. (1950): The Authoritarian Personality, New York: Harper and Row.

Altemeyer, R. (1981): Right-Wing Authoritarianism, Manitoba: University of Manitoba Press.

Allport, G. W. (1958): The Nature of Prejudice, Garden City: Anchor Books.

ANDERson, B. (1991): Imagined Communities, Verso.

Ashmore, R. D., y Del Boca, F. K. (1976): «Psychological Approaches to Understanding Intergroup Conflicts», en P. A. Katz (ed.), Towards the elimination of racism, New York: Pergamon, pp. 72-123.

Billig, M. (1986): «Racismo, prejuicio y discriminación», en S. Moscovici (ed.), Psicología social, vol. II, Barcelona: Paidós, pp. 575-600.

- (1987): Arguing and Thinking: a Rhetorical Approach to Social Psychology, Cambridge: Cambridge University Press.

- (1991): Ideology and Opinions: Studies in Rhetorical Psychology, London: Sage.

- (1992): Talking of the Royal Family, London: Routledge.

BLAU, P. (1977): Inequality and heterogeneity, New York: Free Press.

Breuilly, J. (1982): Nationalism and the State, Manchester.

BurkitT, I. (1994): "The shifting concept of the self», en History of Human Sciences, vol. 7, pp. 7-28.

CalHoun, C. (1991): «Imagined communities and indirect relationships: large-scale social integration and the transformation of every day life», en P. Bourdieu y J. S. Coleman (eds.), Social Theory for a Chenging Society, Nueva York: Rusell Sage Found, pp. 95-121.

- (1993): «Nationalism and Ethnicity», en Annual Rev. of Sociology, pp. 211-239.

- (1994): «Nationalism and Civil Society: Democracy, Diversity and Self-Determination», en C. Calhoun (ed.), Social Theory and the Politics of Identity, Cambridge (MASS), pp. 304335.

Cantor, N.; Mischel, W., y SChWARTZ, J. (1982): «Social Knowledge: structure, content, use and abuse», en A. H. Hastorf y A. M. Isen (eds.), Cognitive Social Psychology, New York: Elsevier.

Correa, N., et al. (1994): La psicología social, pasión inútil del Estado terapéutico, Anthropos, n. ${ }^{\circ} 156$, pp. 33-38.

Crespo, E. (1995): Introducción a la Psicología Social, Madrid: Ed. Universitas.

Deutsch, K. W. (1953): Nationalism and Social Communications: An Inquiry into the Foundations of Nationality, Cambridge: MIT Press.

DumOnT, L. (1982): Essays on Individualism, Chicago University Press.

Elias, N. (1982): The Civilizing Process. Vol. II. Power and Civility, New York: Pantheon Books. - (1991): The Society of Individuals, Oxford: Blackwell.

Forbes, H. D. (1986): Nationalism, Ethnocentrism and Personality, Chicago: Chicago University Press.

Foucault, M. (1980): Power/Knowledge, Brighton: Harvester.

FreUd, S. (1964): "Group psychology and the analysis of the ego", en Standard Edition of the Complete Psychological Works, vol. 13, London: Hogarth Press. 
Gadamer, H. G. (1979): Truth and Method, London: Sheed and Ward.

Gellner, E. (1964): Thought and Change, London: Weindelfeld and Nicholson.

- (1983): Nations and Nationalism, Ithaca, NY: Cornell University Press.

GidDENS, A.: The Nation-State and Violence, University of California Press.

- (1993): «La vida en una sociedad post-tradicional», Revista de Occidente, Madrid, n. ${ }^{\circ}$ 150, pp. 61-90.

HABERMAS, J. (1981): La transformación estructural de la vida pública, Barcelona: Gustavo Gili.

Hall, S. (1986): «Variants of Liberalism», en J. Donald y S. Hall (eds.), Politics and Ideology, Milton Keynes, Open Univ. Press.

Heidegger, M. (1977): "The age of the world picture», en M. HeIDEgGer, The question concerning technology, and other essays, New York: Harper and Row, pp. 115-154.

KoHn, H. (1949): Historia del Nacionalismo, México: FCE.

LAMO DE Espinosa, E. (1993): «La interacción reflexiva», en E. Lamo de Espinosa y J. E. Rodríguez (eds.), Problemas de Teoría Social Contemporánea, Madrid: CIS, pp. 387-434.

Lamo de Espinosa, E., et al. (1994): La Sociología del Conocimiento y de la Ciencia, Madrid: Alianza Editorial.

MarX, K., y Engels, F. (1975): Manifiesto Comunista, Madrid: Ayuso.

Mead, G. H. (1965): Espíritu, Persona y Sociedad, Buenos Aires: Ed. Paidós (ed. orig. 1934).

Mennell, S. (1994): "The Formation of We-images: a Process Theory», en C. Calhoun (ed.), Social Theory and the Politics of Identity, Cambridge (MASS), pp. 175-197.

MLINAR, Z. (1992): "Individuation and Globalization: the Transformation of Territorial Social Organization", en Z. Mlinar (ed.), Globalization and Territorial Identities, England: Avebury, pp. 15-34.

Nisbet, R. (1976): Social change and History, New York: Oxford University Press.

Pinillos, J. L. (1989): «El problema de las mentalidades», en A. Rodríguez y J. Seoane, Tratado de Psicologia General. Tomo 6: Creencias, actitudes y valores, Madrid: Alhambra Universidad, pp. 451-468.

Potter, J., y Wetherell, M. (1987): Discourse and Social Psychology: beyond attitudes and behaviour, London: Sage.

RAmíreZ, S. (1989): "En torno al concepto grupal de nación: una lectura psicosocial», en A. Pérez-Agote (ed.), Sociología del Nacionalismo, Vitoria: Servicio Editorial de la Universidad del País Vasco, pp. 253-258.

- (1992): Hacia una psicología social del nacionalismo, Madrid: Ed. Universidad Complutense.

RoKeach, M. (1982): «El dogmatismo», en J. R. Torregrosa y E. Crespo (eds.), Estudios básicos en psicología social, Barcelona: Hora-CIS, pp. 315-327.

Rosenau, J. N. (1990): Turbulence in World Politics: A Theory of Change and Continuity, Princeton: Princeton Univ. Press.

SCHWARTZ, B. (1990): "The Reconstruction of Abraham Lincoln", en D. Middleton y D. Edwards (eds.), Collective remembering, London: Sage, pp. 81-107.

Segal, D. A., y Handler, R. (1992): "How European is Nationalism», en Social Analysis, diciembre, pp. 1-15.

SHERIF, M., et al. (1961): Intergroup Cooperation and Conflict: the Robber's Cave Experiment, Norman (Ok): University of Oklahoma Press.

Smith, A. (1976): Las teorías del nacionalismo, Barcelona: Ed. Península.

SOMERS, M. R., y GibSON, G. D. (1994): «Reclaiming the Epistemological "Other": Narrative and the Social Constitution of Identity", en C. Calhoun (ed.), Social Theory and the Politics of Identity, Cambridge (MASS), pp. 37-99.

STEIN, H. F. (1990): "The indispensable enemy and american-soviet relation», en V. D. Volkan et al. (eds.), The Psychodinamics of international relations: Vol. I, Concepts and Theories, Lexington, MA: Lexington Books.

SWAAN, A. de (1995): «Widening circles of Identification: Emotional Concerns in Sociogenetic Perspectic», en Theory, Culture and Society, vol. 12, pp. 25-39.

Tajfel, H. (1981): Human Groups and Social Categories, Cambridge: Cambridge University Press. TAYLOR, C. (1992): Multiculturalism and the Politics of Recognition, Princeton: Princeton Univ. Press. 
Tiryakian, E. A. (1989): «Nacionalismo, Modernidad y Sociología», en A. Pérez-Agote (ed.), Sociología del nacionalismo, Vitoria: Servicio Editorial de la Universidad del País Vasco, pp. 143-161.

TORRegrosa, J. R. (1983): «Sobre la identidad personal como identidad social», en Torregrosa y Sarabia (eds.), Perspectivas y contextos de la psicología social, Barcelona: Ed. Hispano Europeo, pp. 217-236.

- (1984): «Introducción», en Torregrosa y Crespo (eds.), Estudios básicos de psicología social, Barcelona: Ed. HORA.

VolTAire, F. M. (1763): Tratado sobre la tolerancia.

WALKER, R. B. J. (1993): Insideloutside: international relations as political theory, Cambridge: Cambridge University Press.

WALLERSTEIN, I. (1988): "The construction of peoplehood: racism, nationalism, ethnicity", en E. Balibar e I. Wallerstein, Race, Nation, Class: Ambiguous Identities, Londres: Verso, pp. 71-85.

Weber, E. (1976): Peasants into Frenchmen, Standford: Standford Univ. Press.

Wetherell, M., y Potter J. (1992): Mapping the Language of Racism: Discourse and the legitimation of explotation, London: Harvester/Wheatsheaf.

Wiley, N. (1994): "The politics of identity in american history», en C. Calhoun (ed.), Social Theory and the Politics of Identity, Cambridge (MASS), pp. 130-149.

\section{RESUMEN}

La Sociología, hasta hace pocas décadas ausente del debate académico sobre Naciones y Nacionalismos, ha prestado escasa atención a la relación Nacionalismo-Modernidad, desatendiendo de este modo el contexto inter(-)nacional en que se ha gestado la «invención de la tradición». Con ello, el sujeto nacionalista ha sido caracterizado unas veces como heredero de la lealtad incondicional a una etnia premoderna; otras, como reacción al proceso expansivo y universalista de la Razón Ilustrada; casi siempe, como encarnación de la idea de "prejuicio» manejada por la Psicología Social (en versión modificada del uso que los enciclopedistas hicieran del término).

Pretendo aquí plantear la conveniencia de una aproximación no psicologista al tema del Nacionalismo, aproximación que, en diálogo crítico con los estudios clásicos sobre "prejuicio», sitúe al sujeto — descentrado y ambivalente- en los espacios contingentes de la Modernidad, y nos disuada de trazar — con la contundencia del pasado - rígidas líneas de separación entre «nacionalistas» e «internacionalistas».

\section{ABSTRACT}

Until a few decades ago, Sociology was not a part of the academic debate on Nations and Nationalism. As such, it has paid scant attention to the relationship between Nationalism and Modernity, thus failing to take into account the inter(-)national context from which the «invention of tradition» sprang. As a result, nationalism has sometimes been characterised as the offshoot of absolute loyalty to pre-modern ethnicity and sometimes as a reaction to the expansive and universalist process of the Age of Enlightenment. But it has almost always been characterised as the incarnation of "prejudice» as defined in social psychology (a variation of the explanation propounded by encyclopedists).

The author recommends taking a non-psychological approach to Nationalism, one which, in conjunction with an objective approach to classical studies on "prejudice», places the subject - disoriented and ambivalent - in the contingent spaces of Modernity and dissuades us from etching — with the conclusiveness of the past - rigid lines separating "nationalists» and «internationalists». 